Research Article

\title{
Polyaniline Supported Ag-Doped ZnO Nanocomposite: Synthesis, Characterization, and Kinetics Study for Photocatalytic Degradation of Malachite Green
}

\author{
Fikradis Habtamu, ${ }^{1}$ Sintayehu Berhanu $\mathbb{D},{ }^{2}$ and Teshome Mender ${ }^{2}$ \\ ${ }^{1}$ Department of Chemistry, Wollega University, Nekemte P.O. Box: 395, Nekemte, Ethiopia \\ ${ }^{2}$ Department of Chemistry, Bonga University, P.O. Box 334, Bonga, Ethiopia \\ Correspondence should be addressed to Sintayehu Berhanu; sintayehuberhanu38@gmail.com
}

Received 15 June 2021; Accepted 20 August 2021; Published 8 September 2021

Academic Editor: Ibrahim H. Alsohaimi

Copyright (c) 2021 Fikradis Habtamu et al. This is an open access article distributed under the Creative Commons Attribution License, which permits unrestricted use, distribution, and reproduction in any medium, provided the original work is properly cited.

$\mathrm{Ag}-\mathrm{ZnO} / \mathrm{PANI}$ nanocomposite was prepared via the sol-gel technique following in situ oxidative polymerization of polyaniline (PANI). XRD, UV-Vis, and FT-IR spectroscopy were employed to study the crystal size, bandgap energy, and bond structure of assynthesized nanocomposites. The mean crystallite size of the nanocomposite determined from XRD was $35.68 \mathrm{~nm}$. Photocatalytic degradation of malachite green (MG) dye using as-synthesized photocatalysts was studied under visible light irradiation. The highest degradation efficiency was recorded for Ag-ZnO/PANI nanocomposites (98.58\%) than Ag-ZnO nanoparticles (88.23\%) in $120 \mathrm{~min}$. The kinetics of photocatalytic degradation of MG follows pseudo-first-order reaction with rate order of $1.1610^{-2} \mathrm{~min}^{-1}$. Moreover, the photocatalytic activity of $\mathrm{Ag}-\mathrm{ZnO} / \mathrm{PANI}$ nanocomposites was evaluated and compared with Ce-Cd oxide, electrospun $\mathrm{P}(3 \mathrm{HB})-\mathrm{TiO} 2$, and with other catalysts in the literature. The optimal conditions for photocatalytic degradation are as follows: the concentration of malachite green $(0.2 \mathrm{~g} / \mathrm{l}), \mathrm{pH}(8)$, and the concentration of catalyst load $(0.2 \mathrm{~g} / \mathrm{l})$ under visible light with an irradiation time of $120 \mathrm{~min}$.

\section{Introduction}

Malachite green (MG) is an organic compound that has arisen as a dubious agent in hydroponics in aquaculture, and it is utilized as a dyestuff for coloring materials such as cotton silk, paper, wool, and leather [1]. It is strongly dissolvable in water and ethanol to form blue-green solutions. Dye-contaminated wastewaters mostly enter the environment as discharges, and their release into the environment in processing wastewater poses a serious risk to both human health and the ecosystem [2-8]. MG has strong effects on the immune and reproductive systems and exhibits potential carcinogenic and genotoxic effects [9]. There are a range of methodologies, such as physical (adsorption), biodegradation, chemical, and electrochemical techniques, that have been developed to eliminate these pollutants from wastewater. However, they are nondestructive, since they just transfer organic compounds from water to another phase, thus causing secondary pollution.

Heterogeneous semiconductor photocatalysis is the most extensively read technique for the degradation and decolorization of numerous wastes in the watery medium under UV-Visible light $[10,11]$. It takes out defilements as opposed to just moving them to another stage without the usage of possibly hazardous oxidants [12]. Photocatalysis is started by photons from UV light, which cause the electrons on the superficial of the photocatalyst to become excited in the valance band; these cause the electrons to go up into the conduction band and then leave positive openings [13]. The produced electron/hole pair incites a complex arrangement of reactions that can bring about the total degradation of 
organic contaminants, for example, a dye adsorbed on the semiconductor surface $[14,15]$.

In such a manner, the use of photocatalysis gives off an impression of being a really engaging methodology for the decomposition of poisonous mixtures (toxic compounds) to nonhazardous products $[2-8,16-18]$.

$\mathrm{ZnO}$ is a significant semiconductor material with a wide bandgap $(3.37 \mathrm{eV})$ and enormous excitation binding energy $(60 \mathrm{eV})$, effective nonlinear resistance, and better thermal conductivity $[19,20]$. $\mathrm{ZnO}$ has a few limitations including the quick recombination rate of photogenerated electronhole pairs, low quantum yield in the photocatalytic reaction in aqueous solution, and photocorrosion which impede the commercialization of the photocatalytic degradation process.

Even if various modification techniques are reported in the literature, neither metal nor nonmetal doping alone can solve the above problems; there is still a dearth of knowledge on metal-nonmetal codoping. Reports related to $\mathrm{Cr}-\mathrm{N}$ codoped $\mathrm{ZnO}, \mathrm{Cr}$-doped $\mathrm{ZnO}$, or $\mathrm{N}$-doped $\mathrm{ZnO}$ are well documented [21, 22].

Conducting polymers (CPs) are appreciably used as adsorbents for the removal of heavy metal ions or dyes from waste water and have attracted great attention due to facile synthesis, electrical conductivity, porosity and low fabrication cost, and environmental stability. Among the conductive polymers (CPs), polyaniline (PANI) was picked as one of the promising conductive polymers to tune composites' optical, electrical, and photocatalyst properties [23]. However, it possessed poor life span owing to the fragile backbone chain. There for synthesizing PANI/ZnO composite photocatalysts has benefits of the capacity to prevent corrosion dissolution of $\mathrm{ZnO}$ during photocatalysis as well as the capacity to empower photocatalysis under solar irradiation due to a decreased bandgap [24].

There are earlier reports on the improvement of the electronic properties and catalytic potential of $\mathrm{ZnO}$ by introducing noble metals such as silver, gold, platinum, and palladium $[25,26]$. Among these, silver merits exceptional consideration due to its stability, conductivity, nontoxic nature, and comparatively less expensive. The incorporation of Ag-doped $\mathrm{ZnO}$ nanoparticles in the polymer matrix upgrades the mechanical properties and conductivity of polymer composite $[27,28]$. Doping factor is another parameter to amplify the conducting properties of the inorganic filler. Subsequently, in the present study, $\mathrm{Ag}-\mathrm{ZnO} /$ PANI composites have synthesized via the chemical oxidative in situ polymerization process of metal nanoparticles with the monomer unit.

To the best of our knowledge, there is no study in the literature that investigates the reaction kinetics of photocatalytic degradation of malachite green using polyaniline/ Ag-ZnO nanocomposite to improve optical and photocatalytic performance. Thus, this research was deliberated to synthesize the photocatalysts by incorporating Ag and PANI comodified $\mathrm{ZnO}$ nanoparticles and discovering the optical properties and kinetics of the photocatalytic activity under visible light irradiation for the degradation and decolorization of MG dye.

\section{Experimental}

2.1. Materials. All chemicals were analytical grade (SigmaAldrich) and used as received without further purification: $\mathrm{Zn}(\mathrm{II})$ acetate dehydrate $\left(\mathrm{ZnC}_{4} \mathrm{H}_{6} \mathrm{O}_{4}, \mathrm{MW}: 183.48 \mathrm{~g} / \mathrm{mol}\right)$, silver nitrate $\left(\mathrm{AgNO}_{3}, \mathrm{MW}: 169.87 \mathrm{~g} / \mathrm{mol}\right)$, oxalic acid $\left(\mathrm{C}_{2} \mathrm{H}_{2} \mathrm{O}_{4}, \mathrm{MW}: 90.03 \mathrm{~g} / \mathrm{mol}\right)$, sulphuric acid $\left(\mathrm{H}_{2} \mathrm{SO}_{4}, \mathrm{MW}\right.$ : $98 \mathrm{~g} / \mathrm{mol}$ ), sodium hydroxide ( $\mathrm{NaOH}, \mathrm{MW}: 40 \mathrm{~g} / \mathrm{mol}$ ), aniline $\left(\mathrm{C}_{6} \mathrm{H}_{5} \mathrm{NH}_{2}, \mathrm{MW}: 93.13 \mathrm{~g} / \mathrm{mol}\right), \mathrm{HCl}(\mathrm{MW} 36.46 \mathrm{~g} / \mathrm{mol}$ ), ethanol $\left(\mathrm{C}_{2} \mathrm{H}_{5} \mathrm{OH} \mathrm{MW} 46.07 \mathrm{~g} / \mathrm{mol}\right)$, ammonium per sulfate $\left.\left(\mathrm{NH}_{4}\right)_{2} \mathrm{~S}_{2} \mathrm{O}_{8} \mathrm{MW} 228.18 \mathrm{~g} / \mathrm{mol}\right)$, and malachite green $\left(\mathrm{C}_{23} \mathrm{H}_{25} \mathrm{~N}_{2}, \mathrm{MW}: 364.911 \mathrm{~g} / \mathrm{mol}\right)$. The structural formula for $\mathrm{MG}$ is given in Figure 1).

\subsection{Synthesis of Photocatalyst}

2.2.1. Synthesis of $A g$-Doped $\mathrm{ZnO}$ Nanoparticle. Silver-doped zinc oxide (Ag-doped $\mathrm{ZnO}$ ) nanoparticles were prepared by a sol-gel method [29]. About $50 \mathrm{mmol}$ of Zn(II) acetate dehydrate was dissolved in ethanol $(100 \mathrm{ml})$, and the solution was stirred for $30 \mathrm{~min}$.

Oxalic acid dehydrate $(2.51 \mathrm{~g})$ was dissolved in ethanol $(40 \mathrm{ml})$, and the solution was added slowly with constant stirring to the above $\mathrm{Zn}$ (II) acetate dehydrate solution. After the addition of oxalic acid, a white sol was formed, and the stirring was continued for three hours. To this, $2 \mathrm{wt} \%$ of silver nitrate $\left(\mathrm{AgNO}_{3}\right)$ was added and stirred for a further three hours. Sol was dried on a waterbath to form xerogel.

The xerogel was then calcined at $500^{\circ} \mathrm{C}$ in a muffle furnace at a heating rate of $5^{\circ} \mathrm{C} / \mathrm{min}$ and held at this temperature for $120 \mathrm{~min}$. Then, it was grinded by using the mortar and pestle. The powder was kept in the desiccator at room temperature.

2.2.2. Synthesis of $\mathrm{Ag}-\mathrm{ZnO} / \mathrm{PANI}$ Nanocomposite. $1 \mathrm{~g}$ of Agdoped $\mathrm{ZnO}$ nanoparticles was added into $100 \mathrm{ml}$ of $1 \mathrm{M} \mathrm{H}_{2} \mathrm{SO}_{4}$. $1 \mathrm{ml}$ of aniline was added drop wise to the solution and stirred for $30 \mathrm{~min}$ until a silvery white color was formed. A solution of $2 \mathrm{~g}$ of ammonium per sulfate (APS) oxidant in $100 \mathrm{ml} \mathrm{H}_{2} \mathrm{SO}_{4}$ solution was added in drop wise under a refrigerator and stirred for $30 \mathrm{~min}$. The solution was changed into dark green color confirming the formation of $\mathrm{Ag}-\mathrm{ZnO} / \mathrm{PANI}$ hybrid. It was kept at room temperature for $24 \mathrm{hrs}$. On the next day, the solution was filtered and washed with distilled water until the filtrate becomes colorless. The precipitated material was filtered and dried in a vacuum oven at $80^{\circ} \mathrm{c}$ for 6 hours [30].

\subsubsection{Characterization of As-Synthesized Photocatalysts.} X-ray diffraction patterns were obtained using a BRUKER D8 (West Germany and equipped with $\mathrm{Cu} \mathrm{K} \alpha$ radiation $(\lambda=1.5405 \AA)$ at room temperature in the scan range $2 \theta$ between 10 and $90^{\circ}$. Accelerating voltage and the applied current were $40 \mathrm{kV}$ and $30 \mathrm{~mA}$, respectively. The absorbance of the photocatalysts was recorded by the Sanyo UV-Vis spectrophotometer model (SP65, UK). $0.2 \mathrm{~g}$ of the photocatalyst was dissolved in $100 \mathrm{ml}$ of deionized water. The absorbance was measured using a quartz tube with a scanning range of 400-800 nm. Fourier transform infrared (FT-IR) spectroscopy was used in the region between 4000 and $400 \mathrm{~cm}^{-1}$ to 


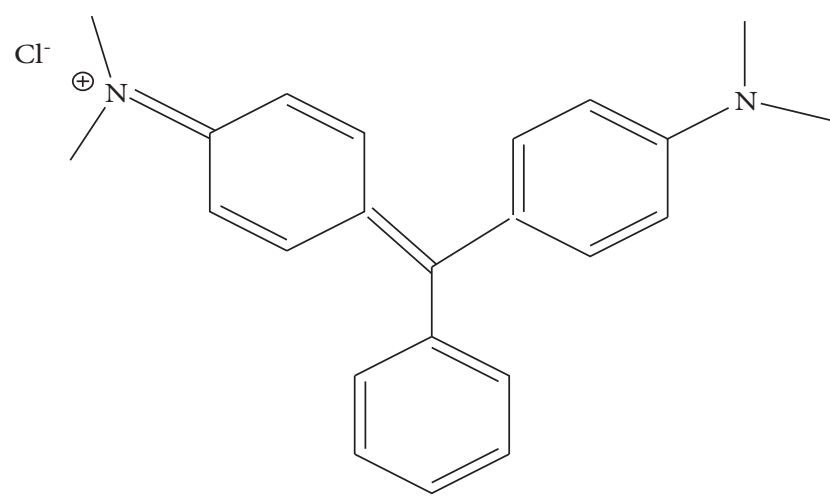

Figure 1: Structural formula of $\mathrm{MG}\left(\mathrm{C}_{23} \mathrm{H}_{25} \mathrm{~N}_{2} \mathrm{Cl}\right)$.

determine the functional groups and surface structure of the samples using a model of Shimadzu 8400S (German). About 5-10 mg of photocatalyst powder was mixed with a drop of paraffin and sandwiched between two $\mathrm{KBr}$ plates to measure the wave number.

2.2.4. Photocatalytic Activity. Catalytic activities of the synthesized photocatalysts were studied for the degradation of malachite green (MG) under dark and visible light. $0.02 \mathrm{~g}$ of $\mathrm{MG}$ was dissolved in $500 \mathrm{ml}$ (at $\mathrm{pH}=8$ and $T=25^{\circ} \mathrm{c}$ ) of deionized water and MG solution was prepared. $0.2 \mathrm{~g}$ of $\mathrm{Ag}$ doped $\mathrm{ZnO}$ nanoparticles and Ag-ZnO/PANI nanocomposite samples were dispersed in $100 \mathrm{ml}$ of MG solution separately and stirred for $30 \mathrm{~min}$ in the dark to establish the adsorption-desorption equilibrium of dye with the catalyst. $\mathrm{NaOH}$ was used to adjust the $\mathrm{pH}$ value of the solution. Then, the reaction was carried out for $120 \mathrm{~min}$ because no further degradation was observed after that. The photocatalytic degradation was assessed by recording the absorbance values at definite time intervals. Percentage degradation of MG dye was calculated using the following formula:

$$
\% \text { of degradation }=\frac{C_{o}-C_{t}}{C_{o}} \times 100,
$$

where $C_{t}$ is the concentration of dye at time $t$ and $C_{o}$ is the concentration of dye at initial stage.

\subsection{Effect of Operational Parameters on the Activities of Photocatalyst}

2.3.1. Initial Concentration of Malachite Green and $p H$. Effect of initial concentration of MG on its degradation was observed by taking the difference dye initial concentrations $0.1-0.5 \mathrm{~g} / \mathrm{L}$ and fixing other parameters constant. And the effect of $\mathrm{pH}$ was also investigated by taking the $\mathrm{pH}$ range from 6 to 10 keeping other parameters constant (photocatalyst load $=0.2 \mathrm{~g}, \mathrm{pH}=8$ ).

2.3.2. Catalyst Load. The effect of catalyst load was observed by taking the difference amount of Ag- ZnO and PANI-Ag$\mathrm{ZnO}$ nanocomposites $(0.1-0.4 \mathrm{~g})$ at constant dye concentration $(0.2 \mathrm{~g} / \mathrm{L})$ and constant $\mathrm{pH}$. The relation between the percent degradation of MG with irradiation time was studied over the reaction time $20-120 \mathrm{~min}$, using a fixed concentration of dye $(50 \mathrm{mg} / \mathrm{L})$, catalyst load $(0.2 \mathrm{~g} / \mathrm{L})$, and $\mathrm{pH} 8$.

2.3.3. Kinetic Studies of Photocatalytic Degradation of $M G$. The kinetics of the photocatalytic degradation of MG solutions was investigated using optimized photocatalyst load, dye initial concentration, and $\mathrm{pH}$ at ultraviolet and visible irradiations.

\section{Results and Discussion}

3.1. X-Ray Diffraction Analysis. The average crystallite size (d) was calculated from the XRD pattern according to the Scherrer equation [31]:

$$
d=\frac{k \lambda}{\beta \cos \theta}
$$

where $k$ is a constant (about 0.9), $\lambda$ is the wavelength $(0.15405 \mathrm{~nm}), \beta$ is the full width at half maximum (FWHM) of the diffraction line, and $\theta$ is the diffraction angle. The XRD patterns of Ag-doped $\mathrm{ZnO}$ nanoparticles showed the crystalline peaks at diffraction angles $2 \theta=31.79,34.44,36.27$, $47.55,62.87,67.97$, and $69.11^{\circ}$ for the diffraction plane from (100), (002), (101), (102), (110), (103), (112), and (201), respectively, and XRD result shows the typical peak patterns of $\mathrm{Ag}-\mathrm{ZnO}$ nanoparticles were wurtzite structure (Figure 2(a)). The peaks at $2 \theta=38.12,38.53,64.45$, and $77.40^{\circ}$ which correspond to the reflection planes of (111), (200), (120), and (311), respectively, show the characteristics of metallic silver $[25,32]$.

The average crystal grain size of Ag-doped $\mathrm{ZnO}$ nanoparticles was at the reflecting peaks of $2 \theta=36.27,38.12$, and $31.79^{\circ}$. Thus, the average size of the nanoparticle becomes $35.68 \mathrm{~nm}$. From the XRD pattern of Ag- $\mathrm{ZnO} / \mathrm{PANI}$ composites, it can be seen that the crystalline peaks of the nanoparticles at $2 \theta=38.06,44.23,64.36$, and $77.4^{\circ}$ correspond to the reflection of (111), (200), (220), and (311), respectively (Figure 2(b)). It was observed that PANI has a broad amorphous nature, and the diffraction peak is located at $2 \theta=25.42^{\circ}$. The average crystal grain size of the composite materials calculated at $2 \theta=38.06,44.23$, and $64.36^{\circ}$ is chosen to determine the average diameter; the average size of the nanoparticle is $31.52 \mathrm{~nm}$. The change in the intensity or broadness of the nanocomposite is due to the strong interfacial interaction between nanoparticles and the polymer matrix.

3.2. UV-Vis Absorption Spectra. UV/Vis absorption spectra of the as-synthesized photocatalysts Ag-ZnO, PANI, and $\mathrm{Ag}-\mathrm{ZnO} / \mathrm{PANI}$ are shown in Figure 3. The bandgap of the catalyst directly influenced the photocatalytic activity in this way that the direct absorption of bandgap photons would lead to the generation of electron-hole pairs within the catalysts; subsequently; the charge carriers started to difuse to the surface of the catalysts. 

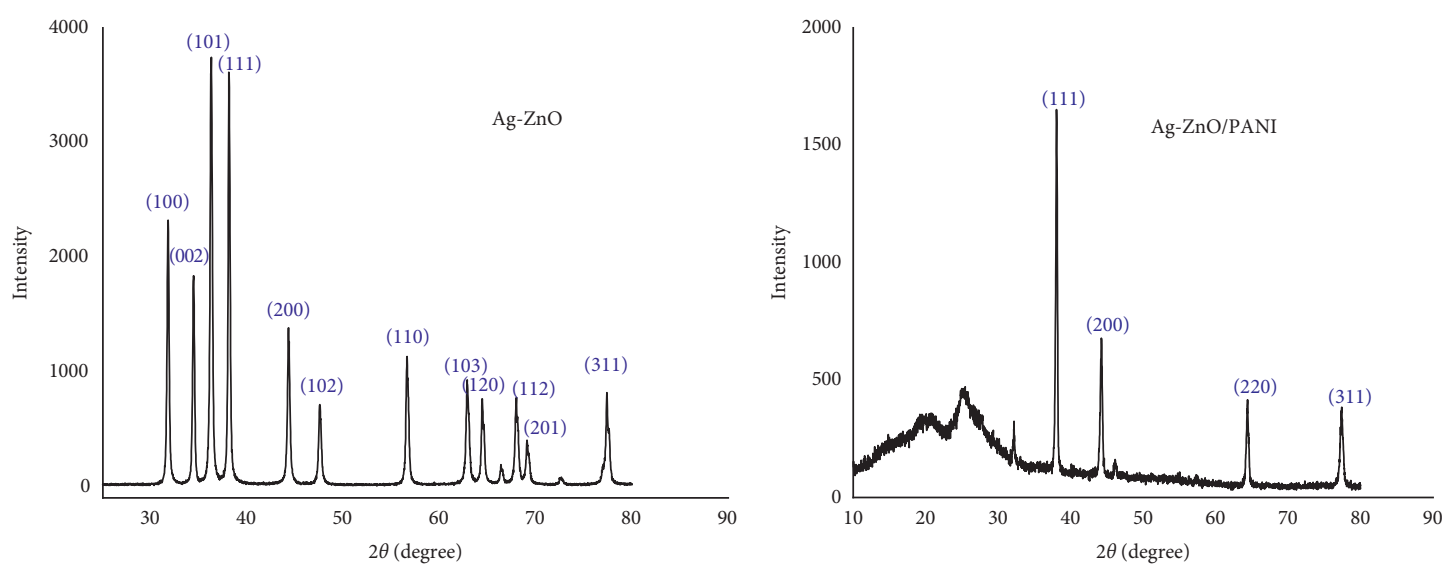

Figure 2: XRD pattern of Ag-ZnO nanoparticle (a) and Ag-ZnO/PANI nanocomposite (b).

This could be due to the bandgap narrowing resulting from the creation of dopant energy levels below the conduction band [33]. The wavelengths of the absorption edges in the UV-Vis spectra were determined by plotting a vertical line from the apex of the curve which is given in Table 1, and the energies are calculated using the following Debye-Scherer's equation

$$
E_{g}(\mathrm{eV})=\frac{1240}{\lambda_{\max }} .
$$

The delocalized metal electron of $\mathrm{Ag} 3 \mathrm{~d}$ state accounts for narrowing bandgap energy of $\mathrm{Ag}-\mathrm{ZnO}$ nanoparticles from $3.2 \mathrm{eV}$ to $2.87 \mathrm{eV}$. Ag-doped $\mathrm{ZnO}$ has also showed a red shift compared to the bare $\mathrm{ZnO}$ nanoparticles by transferring electrons from the conduction band of $\mathrm{ZnO}$ to the conduction band of metal $4 \mathrm{~d}$ states. Addition codoping of PANI enhances further shift in wavelength to large wavelength of $474 \mathrm{~nm}$ and narrowing the bandgap to $2.61 \mathrm{eV}$ of former $\mathrm{Ag}-\mathrm{ZnO} / \mathrm{PANI}$ photocatalysts.

However, some holes are also created in the VB of PANI due to electron transfer from $\mathrm{VB}$ of $\mathrm{PANI}$ to $\mathrm{VB}$ of $\mathrm{Ag} / \mathrm{ZnO}$, as the VB of PANI $(3.25 \mathrm{eV})$ is at higher energy than the VB of $\mathrm{Ag} / \mathrm{ZnO}(2.87 \mathrm{eV})$. The transferred electrons will neutralize some holes in the $\mathrm{VB}$ of $\mathrm{Ag} / \mathrm{ZnO}$. In this way, a certain fraction of the holes in the VB and electrons in the CB of PANI get separated, reducing the chance of recombination and thereby enhancing the chance of photocatalytic activity. This is the advantage of using a coupled system $[33,34]$. Further reduction in the bandgap of the $\mathrm{Ag}-\mathrm{ZnO} / \mathrm{PANI}$ might be due to the synergetic effect of the two dopants $\mathrm{Ag}$ and PANI that control the crystal size and enhance the photo harvesting of nanocomposites.

3.3. FT-IR Analysis. Ag-doped $\mathrm{ZnO}$ shows a peak at the wavenumber from 3400 to $3452 \mathrm{~cm}^{-1}$. The peak at $3442 \mathrm{~cm}^{-1}$ is attributable to the $\mathrm{HO}^{-}$stretching vibration of water and an $\mathrm{O}-\mathrm{H}$ group on the surface of the photocatalyst. The strong absorption peak centered at $508 \mathrm{~cm}^{-1}$ is the metallic stretch assigned to the Ag-doped $\mathrm{ZnO}$.

The symmetric and asymmetric bending modes of C-O bonds were in $1636 \mathrm{~cm}^{-1}$. There were some bands that originated from the presence of water moisture and carbon dioxide in the air in the process of making the pellet (Figure 4(a)). The FT-IR spectrum of Ag-ZnO/PANI shows a strong peak of $\mathrm{Ag}$-doped $\mathrm{ZnO}$ at $609 \mathrm{~cm}^{-1}$.

The absorption band of PANI has occurred at $1126 \mathrm{~cm}^{-1}$. The peak associated with the $\mathrm{N}-\mathrm{H}, \mathrm{C}-\mathrm{H}$, and C-N stretching vibrations is located at 3442,2932 , and $1470 \mathrm{~cm}^{-1}$, respectively. The spectrum at 1293 and $801 \mathrm{~cm}^{-1}$ corresponds to the $\mathrm{C}-\mathrm{N}$ in plane deformation and $=\mathrm{CH}$ in plane vibration (Figure 4(b)) of PANI. Thus, from the FT-IR spectra, it is confirmed that the nanoparticles are well inserted into the macromolecular chain of PANI, and aniline monomers are successfully polymerized on the surface of Ag-doped $\mathrm{ZnO}$ nanoparticles.

\subsection{Photodegradation of Malachite Green under Visible} Irradiation. The photodegradation of malachite green dye was performed for a total of 2 hours under visible light irradiation as shown in Figure 5. The absorption band intensities of the dyes decrease, and this indicated that the dyes have been degraded completely by the photocatalysts. Ag$\mathrm{ZnO} / \mathrm{PANI}$ nanocomposite showed the highest photoactivity (98.58\%) compared with Ag- $\mathrm{ZnO}$ (88.23\%). The pronounced enhancement of the photocatalytic activity of the Ag- $\mathrm{ZnO} / \mathrm{PANI}$ nanocomposites may be attributed to their having more than one path to form electron-hole pairs because of the existence of different interfaces, and the electron-hole recombination prevented to the maximum extent in such system.

The experiments were also realized in dark conditions to understand the effect of the light source when the catalyst material was added into the dyes. As a result, no significant changes were observed in the absorption spectrum of the dyes. Remarkable degradation was observed in visible light.

\subsection{Effect of Operational Parameters on Activities of Photocatalyst}

3.5.1. Initial Concentration of Malachite Green. The effect of the initial concentration of MG on its degradation was observed by taking different initial concentrations from 


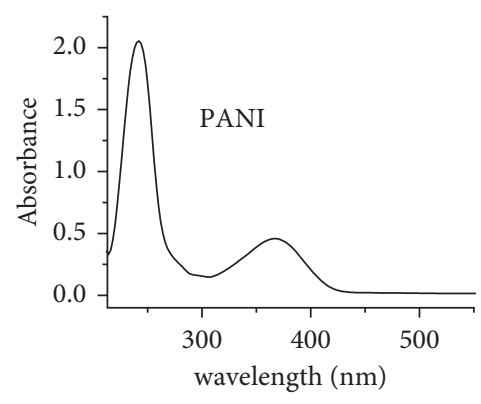

(a)

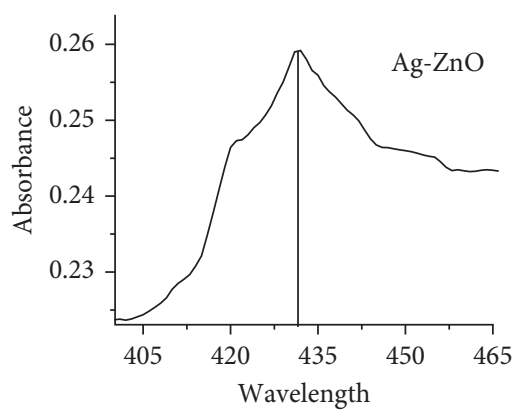

(b)

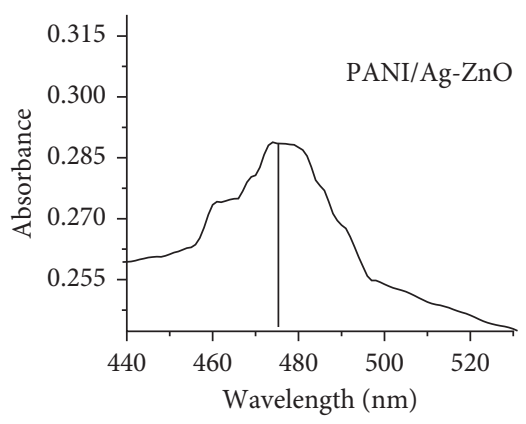

(c)

Figure 3: UV-Visible spectra of PANI (a), Ag/ZnO (b), and Ag-ZnO/PANI nanocomposites (c).

TABLE 1: Absorbance, maximum wavelength, and optical bandgap energy of Ag-ZnO and Ag-ZnO/PANI.

\begin{tabular}{lccc}
\hline Sample photocatalysts & Absorbance & Maximum wavelength (nm) & Band gap energy (eV) \\
\hline PANI & 0.423 & 382 & 3.25 \\
Ag-ZnO & 0.2424 & 432 & 2.87 \\
Ag-ZnO/PANI & 0.2985 & 474 & 2.61 \\
\hline
\end{tabular}

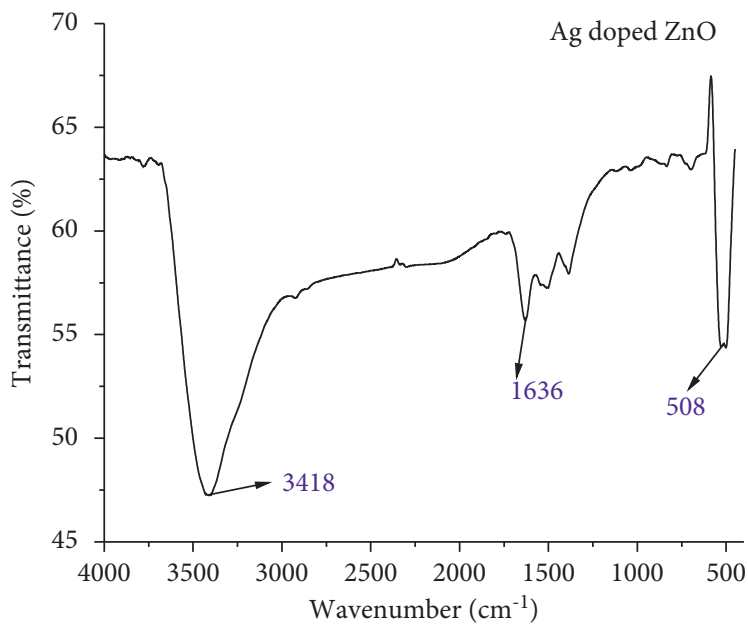

(a)

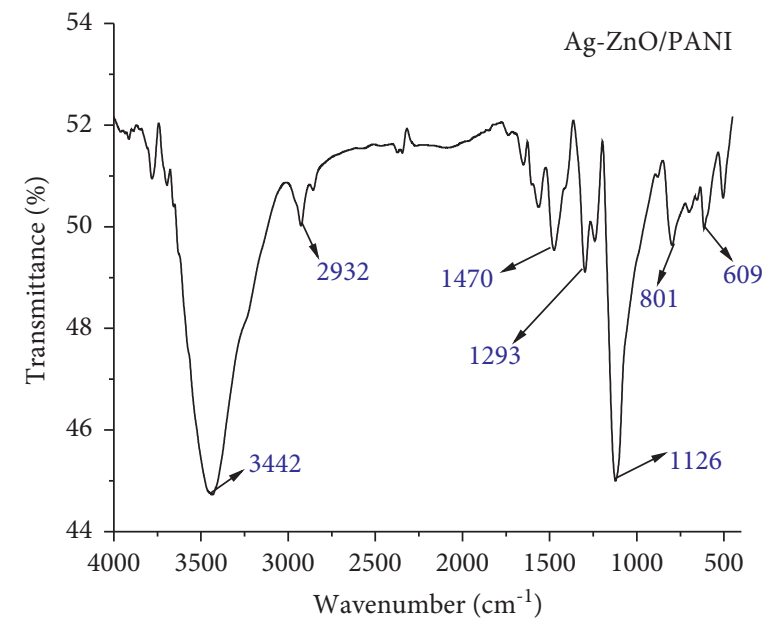

(b)

FIgUre 4: FT-IR spectra of (a) Ag-ZnO nanoparticle and (b) Ag-ZnO/PANI nanocomposite.

$0.1 \mathrm{~g} / \mathrm{L}$ to $0.5 \mathrm{~g} / \mathrm{L}$ and fixing other parameters constant (photocatalyst load $1 \mathrm{mg} / \mathrm{L}, \mathrm{pH}=8$ ) (Table 2). The degradation efficiency of $M G$ was increased with an increase in dye concentration up to $0.2 \mathrm{~g} / \mathrm{L}$ (Figure 6).

Increasing excess dye concentration leads to covering the active sites of the photocatalysts by the dye, and the path length of the photons entering the solution is decreased, resulting in only a few photons reaching the catalyst surface.

Hence, the productions of hydroxyl radicals are reduced. Therefore, the degradation efficiency is reduced [35]. It shows that more dye molecules are adsorbed on the active sites of the photocatalysts. The decrease in degradation above $0.2 \mathrm{~g} / \mathrm{L}$ may be due to the competition of adsorption between dye molecules and dissolved $\mathrm{O}_{2}$ on the catalyst surface.
3.5.2. Catalyst Load. The effect of the photocatalyst loading on the decolorization rate of the dyes was examined by varying the photocatalyst concentration from $0.1 \mathrm{~g} / \mathrm{L}$ to $0.4 \mathrm{~g} / \mathrm{L}$ of the dye solution as shown in Figure 7 at constant dye concentration and constant $\mathrm{pH} 8$.

The degradation of MG initially increases with increase in photocatalyst load from $0.1 \mathrm{~g} / \mathrm{L}$ to $0.2 \mathrm{~g} / \mathrm{L}$. However, further increase of the catalyst load from $0.2 \mathrm{~g} / \mathrm{L}$ to $0.4 \mathrm{~g} / \mathrm{L}$ results in decrease of the degradation of dye. The increase in percent degradation at $0.2 \mathrm{~g} / \mathrm{L}$ is due to the increase in the number of active sites of the photocatalysts. The decrease can be explained by the excess photocatalyst particles that can create a light screening effect that reduces the surface area that is exposed to light illumination and the photocatalytic efficiency [36]. 


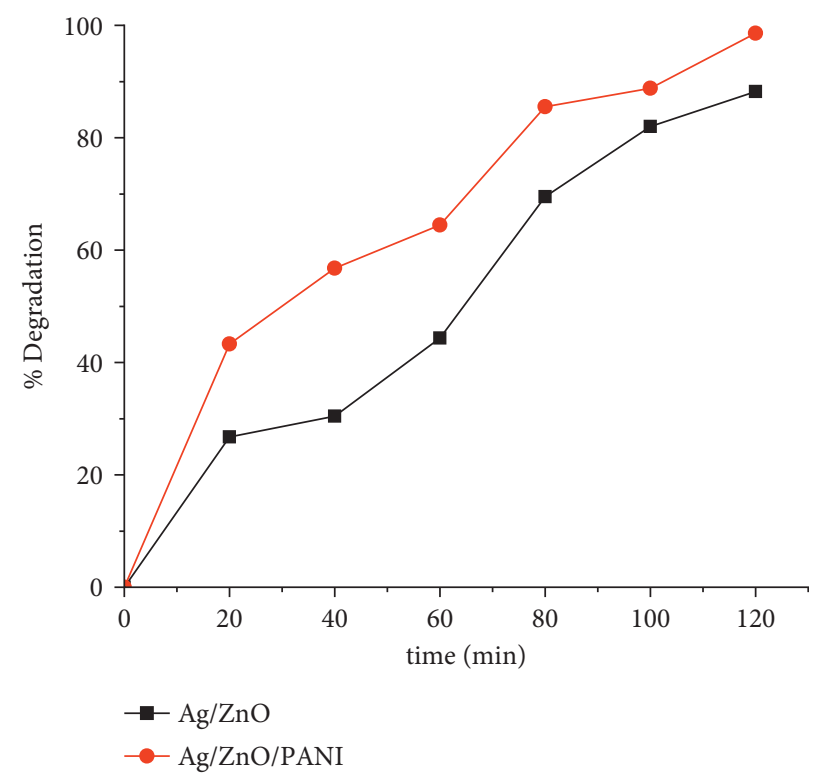

FIgURE 5: Photocatalytic degradation of MG at different irradiation time.

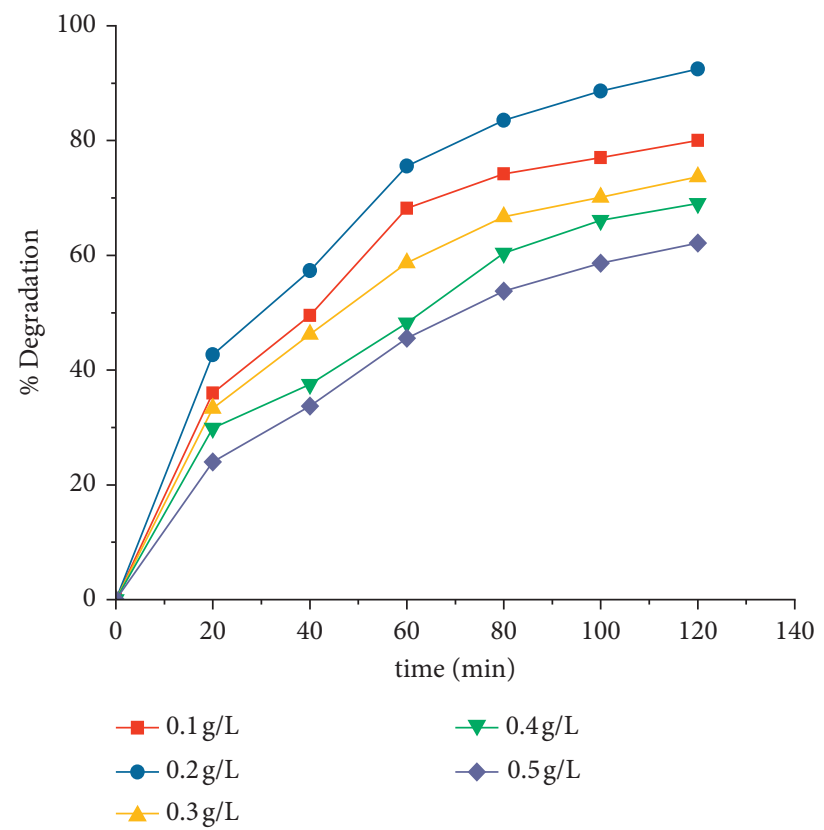

FIgURE 6: Effect of initial concentration on the degradation of MG.

3.6. $p H$. $\mathrm{pH}$ affects the surface charge properties, size of photocatalyst aggregates, and the position of conductance. The effect of $\mathrm{pH}$ on the photocatalytic degradation of MG was investigated by taking the $\mathrm{pH}$ range from 6 to 10 , keeping other parameters constant.

The photocatalyst exhibited a maximum rate of degradation (98.58\%) at $\mathrm{pH}=8$ in 120 min (Figure 8). Therefore, at alkaline $\mathrm{pH}$, the number of hydroxyl groups of the photocatalyst was increased, which facilitates the adsorption of MG. The probable reason for the difference in $\mathrm{pH}$ can be the adsorption of MG onto the catalyst surface depending on its surface area [37].
3.7. Effect of Irradiation Time. The relation between the percent degradation of MG with irradiation time was studied over reaction time from 20 to $120 \mathrm{~min}$, using a fixed concentration of dye $(50 \mathrm{mg} / \mathrm{L})$, catalyst load $(1 \mathrm{mg} / \mathrm{L})$, and $\mathrm{pH}$ of 8 .

It was observed that at $120 \mathrm{~min}$, the dye was completely degraded and becomes colorless. This is due to the fast adsorption rate before the equilibrium is reached; this may be explained by an increased availability in the number of active binding sites on the photocatalyst surface. At the equilibrium stage, the adsorption is likely an attachment-controlled process due to less available sorption sites (Figure 9). 
TABLE 2: Percent degradation of malachite green under dark and solar irradiation with different initial concentrations of nanocomposite and the relation between time and $\ln \left(c / c_{0}\right)$.

\begin{tabular}{lccccccccc}
\hline & \multicolumn{3}{c}{ Initial concentration $(\mathrm{g} / \mathrm{l})$ of Ag-ZnO/PANI } & \multicolumn{3}{c}{$\ln \left(c / c_{0}\right)$} & \multicolumn{2}{c}{ \% of degradation } \\
Time $(\mathrm{min})$ & 0.1 & 0.2 & 0.3 & 0.4 & 0.5 & Ag-ZnO & Ag-ZnO/PANI & Ag-ZnO & Ag-ZnO/PANI \\
\hline 0 & 0 & 0 & 0 & 0 & 0 & 0 & 0 & 0 & 0 \\
20 & 36.01 & 42.68 & 33.34 & 29.88 & 24.012 & 0.3465 & 0.2328 & 26.73 & 43.28 \\
40 & 49.54 & 57.34 & 46.23 & 37.54 & 33.72 & 0.6318 & 0.4331 & 38.46 & 56.75 \\
60 & 68.20 & 75.57 & 58.69 & 48.21 & 45.54 & 1.0181 & 0.7149 & 44.33 & 64.44 \\
80 & 72.21 & 83.54 & 66.73 & 60.39 & 53.74 & 1.3417 & 0.9224 & 69.53 & 85.54 \\
100 & 74.05 & 88.65 & 70.13 & 68.12 & 58.61 & 1.6111 & 1.1586 & 81.98 & 88.78 \\
120 & 77.52 & 92.48 & 73.71 & 70.03 & 62.12 & 1.8782 & 1.3948 & 88.23 & 98.58 \\
\hline
\end{tabular}

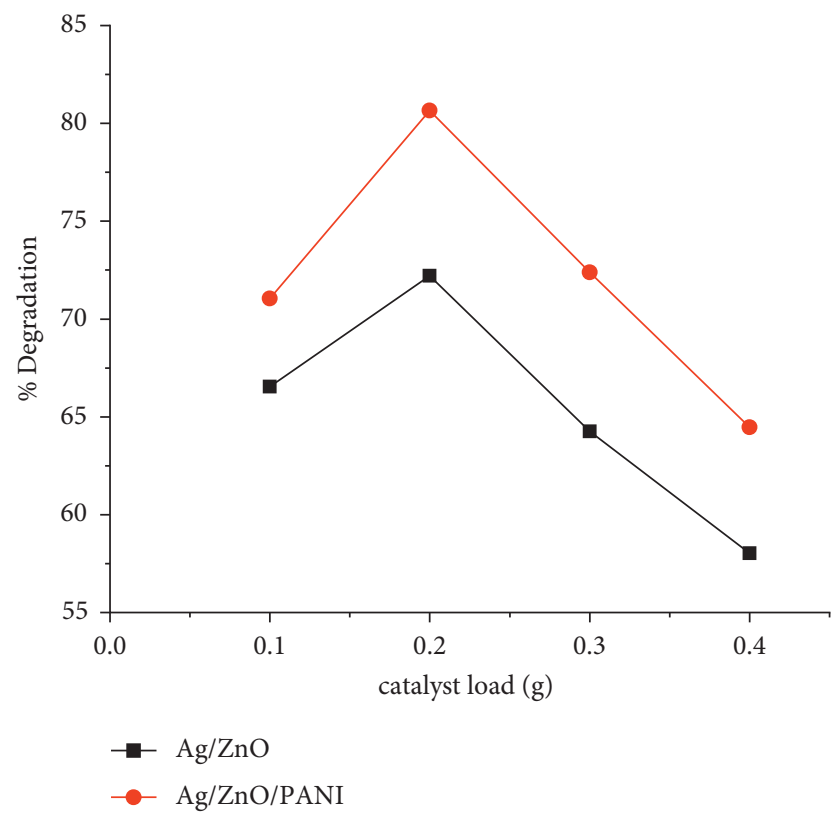

FIGURE 7: Effect of catalyst load on the degradation of MG dye.

3.8. Kinetics of Photocatalytic Degradation of Malachite Green. The kinetic study of the degradation of MG was determined by using different initial concentrations of $\mathrm{MG}$ from 0.1 to $0.5 \mathrm{~g} / \mathrm{L}$. The photocatalytic activity of the synthesized nanocomposites under visible light can be evaluated by comparing the apparent rate constants $[17,38]$ using the following Langmuir-Hinshelwood equation.

$$
\ln \left(\frac{c}{c_{o}}\right)=K_{\mathrm{app}} \cdot t,
$$

where $c_{o}$ and $c$ are the initial and final absorbance of MG, and $K_{\text {app }}$ is the apparent rate constant.

It can be seen that the photocatalytic activity of $\mathrm{Ag}-\mathrm{ZnO} /$ PANI nanocomposites under visible light irradiation is higher than Ag-doped $\mathrm{ZnO}$ nanoparticles. Figure 10 shows the relationship between time and the degradation rate $\left(\ln \left(c_{0} / c\right)\right)$ of $\mathrm{MG}$ for visible light illumination. The regression correlation coefficient $\left(R^{2}\right)$ is found to be 0.9972 for Agdoped $\mathrm{ZnO}$ nanoparticles and 0.9991 for Ag-ZnO/PANI nanocomposite. From the plot, the $K_{\text {app }}$ value for Ag-ZnO nanoparticle and $\mathrm{Ag} / \mathrm{ZnO} / \mathrm{PANI}$ nanocomposite is
$1.56 \times 10^{-2} \mathrm{~min}^{-1}$ and $1.16 \times 10^{-2} \mathrm{~min}^{-1}$, respectively. The kinetics curve was pseudo-first-order with respect to Agdoped $\mathrm{ZnO}$ and $\mathrm{Ag} / \mathrm{ZnO} / \mathrm{PANI}$ nanocomposites.

The proposed mechanism is presented schematically in Figure 11 according to Pham et al., 2020, described in detail as follows [18]. The MG dye adsorbed onto the full photocatalyst. The possible photocatalytic mechanism involves the following steps:

$$
\begin{array}{r}
\text { PANI } \stackrel{\text { hv }}{\longrightarrow}\left(\mathrm{h}_{\mathrm{VB}}^{+}+\mathrm{e}_{\mathrm{CB}}^{-}\right) \text {PANI, } \\
\mathrm{Ag} / \mathrm{ZnO} \stackrel{\mathrm{hv}}{\longrightarrow}\left(\mathrm{h}_{\mathrm{VB}}^{+}+\mathrm{e}_{\mathrm{CB}}^{-}\right) \mathrm{Ag}-\mathrm{ZnO}, \\
\text { Dye } \stackrel{\mathrm{hv}}{\longrightarrow} \mathrm{dye}^{*}, \\
\mathrm{Dye}^{*}+\left(\mathrm{h}_{\mathrm{VB}}^{+}\right) \mathrm{PANI} / \mathrm{Ag}-\mathrm{ZnO} \stackrel{\mathrm{hv}}{\longrightarrow} \mathrm{dye}^{+}, \\
\mathrm{O}_{2}^{-}+\mathrm{H}_{2} \mathrm{O}+\left(\mathrm{h}_{\mathrm{VB}}^{+}\right) \mathrm{PANI} / \mathrm{Ag}-\mathrm{ZnO} \mathrm{H}_{2} \mathrm{O}_{2} \\
\mathrm{H}_{2} \mathrm{O}_{2} \longrightarrow 2 \mathrm{HO}^{\longrightarrow}
\end{array}
$$

The holes present in the $\mathrm{VB}$ of $\mathrm{Ag} / \mathrm{ZnO}$ react with $\mathrm{H}_{2} \mathrm{O}$ to form $\mathrm{H}_{2} \mathrm{O}_{2}$ which leads to the formation of hydroxyl radicals $(\bullet \mathrm{OH})$. It is a powerful oxidant which decomposes effectively 


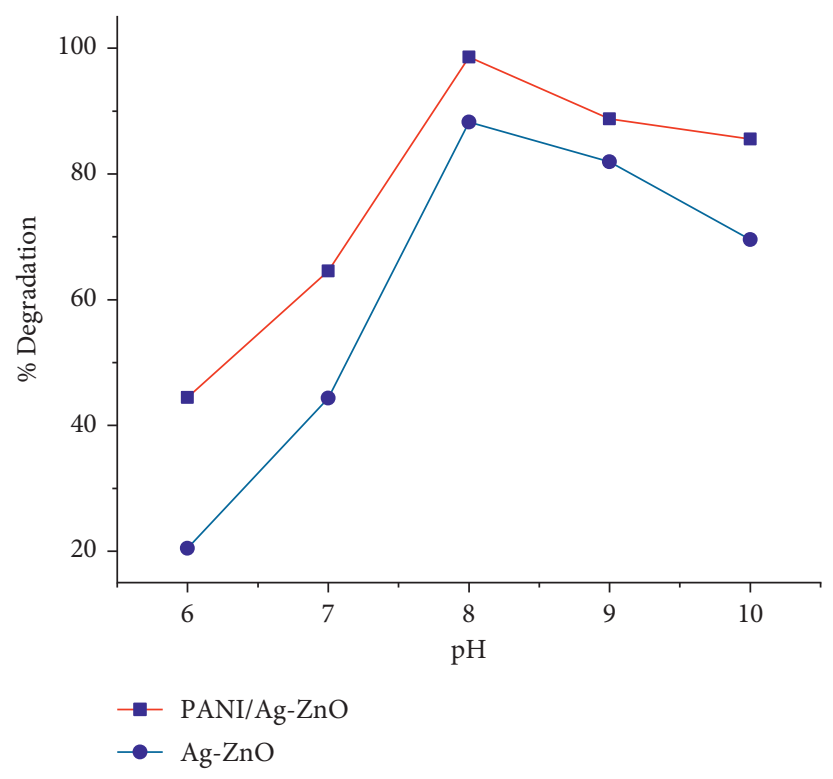

Figure 8: Effect of $\mathrm{pH}$ of the solution on the degradation of MG dye.

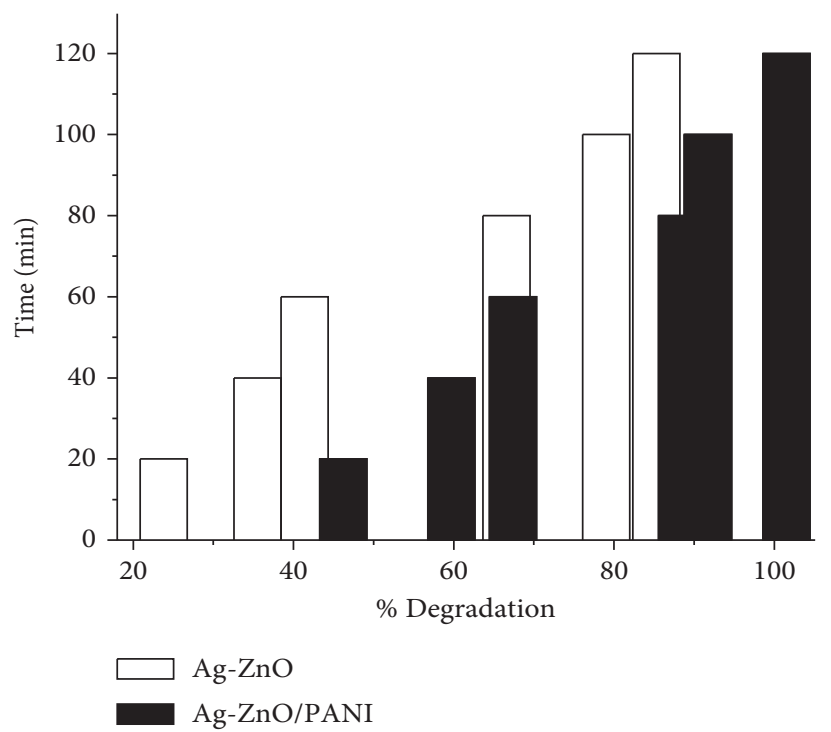

FIgURE 9: Effect of irradiation time on photocatalytic degradation of MG using Ag-ZnO and PANI/Ag-ZnO.

the malachite green into a nontoxic degraded product (such as water and carbon dioxide).

$$
\cdot \mathrm{OH}+\mathrm{Dye}^{+} \longrightarrow \mathrm{H}_{2} \mathrm{O}+\mathrm{CO}_{2} \text { (colourless). }
$$

The role of PANI is clearly observed in movement and reduction of the carrier recombination due to the existence of linking doped $\mathrm{ZnO}$ particles and successive reduction of the surface resistivity of the entire photocatalyst to the photodegradation of MG.
Table 3 provides a short comparison of MG degradation efficiency by different authors using different catalysts through the photocatalytic activity. It could be observed that the degradation efficiency under simulated solar light irradiation by xenon lamp of the PANI/Ag- $\mathrm{ZnO}$ was much higher than those of $\mathrm{Fe}^{3+} / \mathrm{H}_{2} \mathrm{O}_{2}$, electrospun $\mathrm{P}(3 \mathrm{HB})-\mathrm{TiO}_{2}$, Ce-Cd oxide, $\mathrm{TiO}_{2}$, and $\mathrm{ZnO}$ and $\mathrm{CA} / \mathrm{TiO}_{2}$ bio-nanocomposites, and the degradation rate of MG on PANI/Ag$\mathrm{ZnO}$ nanocomposite was also faster. 


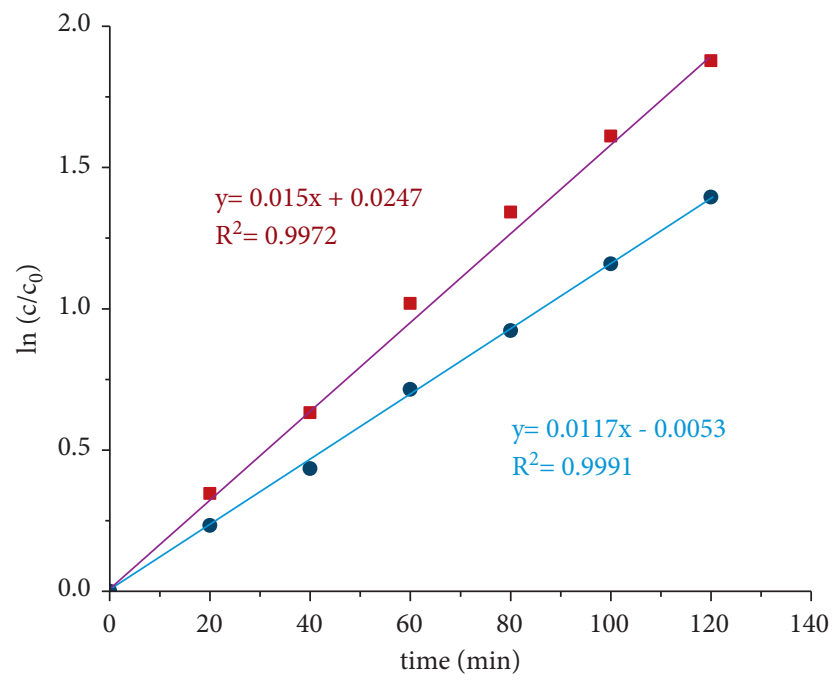

- $\mathrm{Ag}-\mathrm{ZnO}$

- $\mathrm{Ag}-\mathrm{ZnO} / \mathrm{PANI}$

FIGURE 10: Pseudo-first-order kinetics of photocatalytic degradation of MG dye.
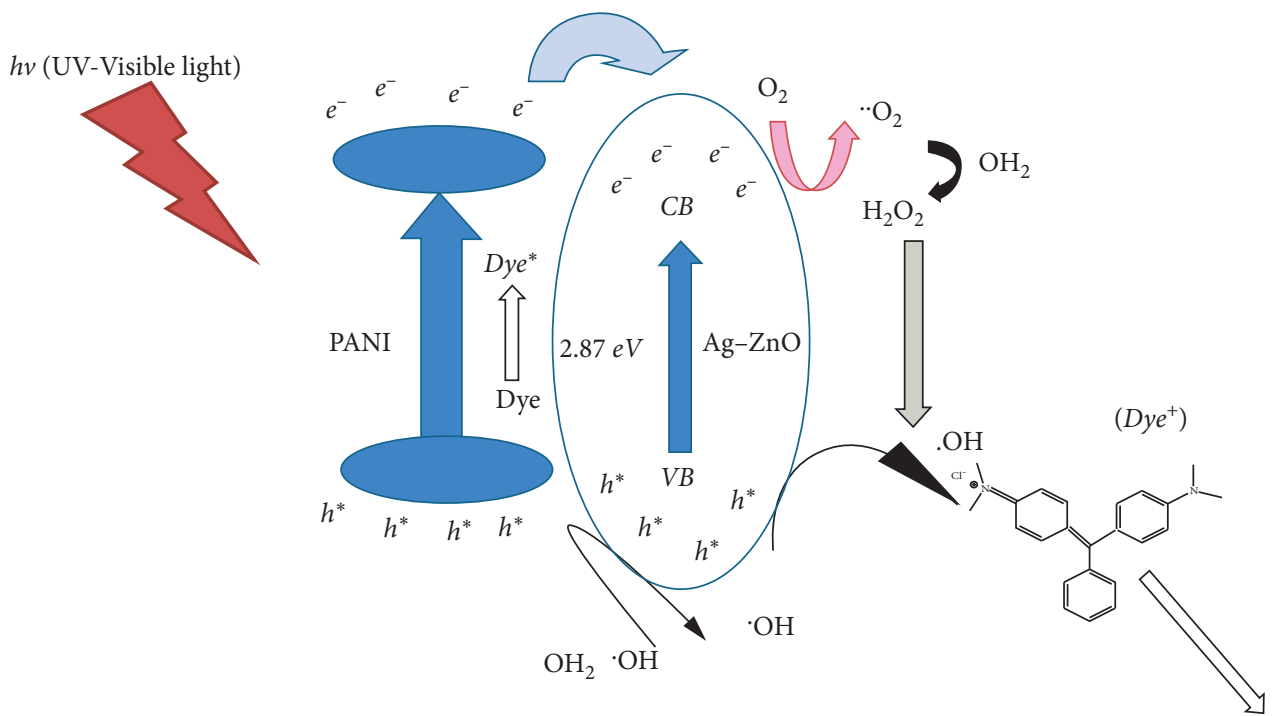

Degraded Product

FIGURE 11: Diagrammatic illustration of the mechanism for MG dyes degradation using the optimized photocatalyst composite by attaching PANI to Ag-doped $\mathrm{ZnO}$ nanoparticles. 
TABLE 3: Comparison of polyaniline/Ag-ZnO nanocomposite for degradation of MG by various catalysts.

\begin{tabular}{|c|c|c|c|}
\hline Catalyst & Reaction condition & Degradation efficiency & Reference \\
\hline $\begin{array}{l}\mathrm{Fe}^{3+} / \mathrm{H}_{2} \mathrm{O}_{2} \text { (fenton-like } \\
\text { oxidation) }\end{array}$ & $\begin{array}{c}(\mathrm{MG})=3 \times 10^{-5} \mathrm{M},\left(\mathrm{Fe}^{3+}\right)=1.0 \times 10^{-3} \mathrm{M},\left(\mathrm{H}_{2} \mathrm{O}_{2}\right)=5 \times 10^{-2} \mathrm{M}, \mathrm{pH}=3 . \\
\text { Under visible light irradiation. }\end{array}$ & $95 \%$ of $\mathrm{MG}$ in $120 \mathrm{~min}$ & [2] \\
\hline $\begin{array}{l}\text { Electrospun P (3HB)- } \\
\mathrm{TiO}_{2}\end{array}$ & $4 \mathrm{~g}$ of $\mathrm{TiO}_{2}$ in $100 \mathrm{~mL}$ of $4 \mathrm{w} / \mathrm{v} \% \mathrm{P}(3 \mathrm{HB})$. Under UV light illumination & $\begin{array}{l}98 \% \text { of MG with in less } \\
\text { than } 2 \mathrm{~h}\end{array}$ & [3] \\
\hline Nanosized Ce-Cd oxide & $\begin{array}{c}(\mathrm{MG})=2.50 \times 10^{-5} \mathrm{M} ; \mathrm{pH}=8.0 \text { with light intensity } 600 \mathrm{Wm}^{-2} ; \text { and } \\
\text { catalyst loading } 0.03 \mathrm{~g} / 50 \mathrm{~mL} .\end{array}$ & 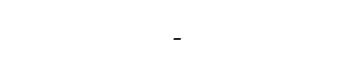 & [4] \\
\hline $\mathrm{Bi}_{2} \mathrm{WO}_{6}$ & $\begin{array}{c}\left(\mathrm{Bi}_{2} \mathrm{WO}_{6}\right)=1.0 \mathrm{~g} \cdot \mathrm{L}^{-1} ;(\mathrm{MG})=10 \mathrm{mg} \mathrm{L} \\
\text { illumination. }\end{array}$ & $\begin{array}{l}\text { The degradation efficiency } \\
98.9 \% \text { in } 30 \mathrm{~min}\end{array}$ & [5] \\
\hline $\begin{array}{l}\text { Microbial consortium } \\
\text { CM-4 }\end{array}$ & $\begin{array}{c}\mathrm{pH}=7.5 \text { at with UV light; no correlation between the percentage of } \\
\text { decolorization and COD removal. }\end{array}$ & $99 \%$ within $2 \mathrm{~h}$ & {$[6]$} \\
\hline $\begin{array}{l}\mathrm{TiO}_{2} \text { and } \mathrm{ZnO} \\
\text { nanoparticles }\end{array}$ & UV lamp (200-600 nm). & $\begin{array}{l}\mathrm{TiO}_{2}(49.35 \%) \text { and } \mathrm{ZnO} \\
(23.31 \% .)\end{array}$ & [7] \\
\hline $\begin{array}{l}\mathrm{CA} / \mathrm{TiO}_{2} \text { bio- } \\
\text { nanocomposites }\end{array}$ & $(\mathrm{MG})=10 \mathrm{ppm}, \mathrm{pH}=7$ using visible light. & $99.5 \%$ in $240 \mathrm{~min}$ & {$[8]$} \\
\hline $\begin{array}{l}\text { Polyaniline/Ag- } \mathrm{ZnO} \\
\text { nanocomposite }\end{array}$ & $\begin{array}{l}\text { Catalyst load }=0.2 \mathrm{~g}, \mathrm{pH}=8 \text { initial concentration of } \mathrm{MG}=0.2 \mathrm{~g} / \mathrm{l} \text {, and } \\
\text { irradiation time }=120 \mathrm{~min} \text { using visible light with light intensity } 120 \\
\mathrm{Wm}^{-2} \text {. }\end{array}$ & 98.58 with $120 \mathrm{~min}$ & This work \\
\hline
\end{tabular}

Therefore, the nanocomposite is likely a decent and environment friendly catalyst in the removal of MG from contaminated (polluted) water.

\section{Conclusions}

PANI/Ag-ZnO nanocomposite was successfully synthesized in situ chemical oxidative polymerization. The FT-IR result proved the strong interfacial interaction between the metal oxide nanoparticles and polar segments of the PANI chain. The $\mathrm{XRD}$ results showed that the amorphous nature of PANI got reduced with an increase in the content of metal oxide nanoparticles. The nanoparticle is $35.68 \mathrm{~nm}$, whereas the nanocomposite is $31.52 \mathrm{~nm}$. Ag- $\mathrm{ZnO}$ has a bandgap of $2.87 \mathrm{eV}$ $(432 \mathrm{~nm})$ and the PANI/Ag-ZnO nanocomposite has $2.61 \mathrm{eV}$ $(474 \mathrm{~nm})$. The photocatalytic activity of the MG was investigated, and a photocatalytic oxidation mechanism was proposed. Ag- $\mathrm{ZnO}$ and $\mathrm{PANI} / \mathrm{Ag} / \mathrm{ZnO}$ degrade the $\mathrm{MG}$ dye $88.23 \%$ and $98.58 \%$, respectively. The highest photocatalytic activity of Ag-ZnO/PANI nanocomposites over $\mathrm{ZnO}$ photocatalysts was qualified due to dopants, low rate of recombination of the photogenerated electrons-holes, as well as its lower crystal size and bandgap energy.

Adding PANI to the Ag-doped $\mathrm{ZnO}$ leads to extra benefits in both surface textures with a high surface area and a simple electron transfer process. The optimal conditions for photocatalytic degradation of malachite green are as follows: the concentration of malachite green is $0.2 \mathrm{~g} / \mathrm{l}$, at $\mathrm{pH}$ of 8 , and the concentration of catalyst load is $0.2 \mathrm{~g} / \mathrm{l}$ under visible light illumination for $120 \mathrm{~min}$. The kinetics of photocatalysis (PANI/Ag-ZnO) is a pseudo-first-order reaction with a positive slope and rate constant of $1.6 \times 10^{-2} \mathrm{~min}^{-1}$. Our PANI-supported $\mathrm{Ag}-\mathrm{ZnO}$ is predictable to be a promising applicant for environmental claims. The prevalent performance for various dye photodegradations and recycling abilities with a similar presentation is profoundly anticipated.

\section{Data Availability}

No data were used to support this study.

\section{Conflicts of Interest}

The authors declare that there are no conflicts of interest.

\section{Acknowledgments}

The authors are grateful for the financial support provided by the Ministry of Science and Higher Education of Ethiopia.

\section{References}

[1] D. Robati, M. Rajabi, O. Moradi et al., "Kinetics and thermodynamics of malachite green dye adsorption from aqueous solutions on graphene oxide and reduced graphene oxide," Journal of Molecular Liquids, vol. 214, pp. 259-263, 2016.

[2] S. Hashemian, "Fenton-like oxidation of Malachite green solutions: kinetic and thermodynamic study," Journal of Chemistry, vol. 2013, Article ID 809318, 7 pages, 2013.

[3] N. Sridewi, Y. F. Lee, and K. Sudesh, "Simultaneous adsorption and photocatalytic degradation of malachite green using electrospun $\mathrm{P}$ (3HB)-TiO2 nanocomposite fibers and films," International Journal of Photoenergy, vol. 2011, Article ID 597854, 11 pages, 2011.

[4] K. L. Ameta, N. Papnai, and R. Ameta, "Synthesis, characterization, and use of novel bimetal oxide catalyst for photoassisted degradation of malachite green dye," Journal of Materials, vol. 2014, Article ID 480107, 5 pages, 2014.

[5] A. Karimi, M. Aghbolaghy, A. Khataee, and S. Shoa Bargh, "Use of enzymatic bio-Fenton as a new approach in decolorization of malachite green," Science World Journal, vol. 2012, Article ID 691569, 5 pages, 2012.

[6] J. Cheriaa, M. Khaireddine, M. Rouabhia, and A. Bakhrouf, "Removal of triphenylmethane dyes by bacterial consortium," The Scientific World Journal, vol. 2012, Article ID 512454, 9 pages, 2012. 
[7] A. K. Singh and U. T. Nakate, "Photocatalytic properties of microwave-synthesized $\mathrm{TiO} 2$ and $\mathrm{ZnO}$ nanoparticles using malachite green dye," Journal of Nanoparticles, vol. 2013, Article ID 310809, 7 pages, 2013.

[8] M. Bahal, N. Kaur, N. Sharotri, and D. Sud, "Investigations on amphoteric chitosan/TiO2 bionanocomposites for application in visible light induced photocatalytic degradation," Advances in Polymer Technology, vol. 2019, Article ID 2345631, 9 pages, 2019.

[9] E. S. Baeissa, "Photocatalytic degradation of malachite green dye using $\mathrm{Au} / \mathrm{NaNbO} 3$ nanoparticles," Journal of Alloys and Compounds, vol. 672, pp. 564-570, 2016.

[10] M. Chen, C. Bao, T. Cun, and Q. Huang, "One-pot synthesis of $\mathrm{ZnO}$ /oligoaniline nanocomposites with improved removal of organic dyes in water: effect of adsorption on photocatalytic degradation," Materials Research Bulletin, vol. 95, pp. 459467, 2017.

[11] A. Pfitzner, S. Dankesreiter, A. Eisenhofer, and M. Cherevatskaya, "12 Heterogeneous semiconductor photocatalysis," in Chemical Photocatalysis, pp. 211-246, De Gruyter, Berlin, Germany, 2013.

[12] H. Zangeneh, A. A. L. Zinatizadeh, M. Habibi, M. Akia, and M. Hasnain Isa, "Photocatalytic oxidation of organic dyes and pollutants in wastewater using different modified titanium dioxides: a comparative review," Journal of Industrial and Engineering Chemistry, vol. 26, pp. 1-36, 2015.

[13] C. Byrne, G. Subramanian, and S. C. Pillai, "Recent advances in photocatalysis for environmental applications," Journal of Environmental Chemical Engineering, vol. 6, no. 3, pp. 35313555, 2018.

[14] T. Welderfael, M. Pattabi, R. M. Pattabi, and A. K. Thilipan, "Photocatalytic activity of Ag-N co-doped $\mathrm{ZnO}$ nanorods under visible and solar light irradiations for MB degradation," Journal of Water Process Engineering, vol. 14, pp. 117-123, 2016.

[15] K. Soutsas, V. Karayannis, I. Poulios et al., "Decolorization and degradation of reactive azo dyes via heterogeneous photocatalytic processes," Desalination, vol. 250, no. 1, pp. 345-350, 2010.

[16] D. Chatterjee and S. Dasgupta, "Visible light induced photocatalytic degradation of organic pollutants," Journal of Photochemistry and Photobiology C: Photochemistry Reviews, vol. 6, no. 2-3, pp. 186-205, 2005.

[17] G. Sharma, Z. A. ALOthman, A. Kumar, S. Sharma, S. K. Ponnusamy, and M. Naushad, "Fabrication and characterization of a nanocomposite hydrogel for combined photocatalytic degradation of a mixture of malachite green and fast green dye," Nanotechnology for Environmental Engineering, vol. 2, no. 1, p. 4, 2017.

[18] T. A. T. Pham, V. A. Tran, V. D. Le et al., "Facile preparation of $\mathrm{ZnO}$ nanoparticles and $\mathrm{Ag} / \mathrm{ZnO}$ nanocomposite and their photocatalytic activities under visible light," International Journal of Photoenergy, vol. 2020, Article ID 8897667, 14 pages, 2020.

[19] M. T. Ramesan and K. Suhailath, "Role of nanoparticles on polymer composites," in Micro and Nano Fibrillar Composites (MFCs and NFCs) from Polymer Blends, pp. 301-326, Woodhead Publishing, Amsterdam, Netherlands, 2017.

[20] H. Sun, X. Feng, S. Wang, H. M. Ang, and M. O. Tadé, "Combination of adsorption, photochemical and photocatalytic degradation of phenol solution over supported zinc oxide: effects of support and sulphate oxidant," Chemical Engineering Journal, vol. 170, no. 1, pp. 270-277, 2011.
[21] S. Colis, H. Bieber, S. Begin-Colin, G. Schmerber, C. Leuvrey, and A. Dinia, "Magnetic properties of Co-doped $\mathrm{ZnO}$ diluted magnetic semiconductors prepared by low-temperature mechanosynthesis," Chemical Physics Letters, vol. 422, no. 4-6, pp. 529-533, 2006.

[22] B. M. Rajbongshi, A. Ramchiary, and S. Samdarshi, "Influence of N-doping on photocatalytic activity of $\mathrm{ZnO}$ nanoparticles under visible light irradiation," Materials Letters, vol. 134, pp. 111-114, 2014.

[23] K. Namsheer and C. S. Rout, "Conducting polymers: a comprehensive review on recent advances in synthesis, properties and applications," RSC Advances, vol. 11, no. 10, pp. 5659-5697, 2021.

[24] O.-G. Vanja, P. Violeta, P.-B. Marijana et al., "Physical properties and biocompatibility of nanostructural biomaterials based on active calcium silicate systems and hydroxyapatite," in Dental Applications of Nanotechnology, pp. 247-271, Springer, Cham, Switzerland, 2018.

[25] D. Li and H. Haneda, "Morphologies of zinc oxide particles and their effects on photocatalysis," Chemosphere, vol. 51, no. 2, pp. 129-137, 2003.

[26] T. K. Pathak, H. C. Swart, and R. E. Kroon, "Structural and plasmonic properties of noble metal doped $\mathrm{ZnO}$ nanomaterials," Physica B: Condensed Matter, vol. 535, pp. 114118, 2018.

[27] B. Bethi, S. H. Sonawane, B. A. Bhanvase, and S. P. Gumfekar, "Nanomaterials-based advanced oxidation processes for wastewater treatment: a review," Chemical Engineering and Processing - Process Intensification, vol. 109, pp. 178-189, 2016.

[28] B. L. Martínez-Vargas, S. M. Durón-Torres, D. Bahena, J. L. Rodríguez-López, J. M. Peralta-Hernández, and A. Picos, "One-pot synthesis of $\mathrm{ZnO}-\mathrm{Ag}$ and $\mathrm{ZnO}-\mathrm{Co}$ nanohybrid materials for photocatalytic applications," Journal of Physics and Chemistry of Solids, vol. 135, Article ID 109120, 2019.

[29] T. Chitradevi, A. Jestin Lenus, and N. Victor Jaya, "Structure, morphology and luminescence properties of sol-gel method synthesized pure and Ag-doped ZnO nanoparticles," Materials Research Express, vol. 7, no. 1, Article ID 015011, 2019.

[30] M. F. Nsib, S. Saafi, A. Rayes, N. Moussa, and A. Houas, "Enhanced photocatalytic performance of Ni-ZnO/Polyaniline composite for the visible-light driven hydrogen generation," Journal of the Energy Institute, vol. 89, no. 4, pp. 694-703, 2016.

[31] A. Monshi, M. R. Foroughi, and M. R. Monshi, "Modified Scherrer equation to estimate more accurately nano-crystallite size using XRD," World Journal of Nano Science and Engineering, vol. 2, no. 3, pp. 154-160, 2012.

[32] K. Takahashi and T. Morizumi, "Growth of InAs whiskers in wurtzite structure," Japanese Journal of Applied Physics, vol. 5, no. 8, pp. 657-662, 1966.

[33] J. Luan and Z. Hu, "Synthesis, property characterization, and photocatalytic activity of novel visible light-responsive photocatalyst," International Journal of Photoenergy, vol. 2012, Article ID 301954, 11 pages, 2012.

[34] S. Kuriakose, V. Choudhary, B. Satpati, and S. Mohapatra, "Facile synthesis of Ag-ZnO hybrid nanospindles for highly efficient photocatalytic degradation of methyl orange," Physical Chemistry Chemical Physics, vol. 16, no. 33, pp. 17560-17568, 2014.

[35] A. Khataee, R. D. C. Soltani, A. Karimi, and S. W. Joo, "Sonocatalytic degradation of a textile dye over Gd-doped $\mathrm{ZnO}$ nanoparticles synthesized through sonochemical process," Ultrasonics Sonochemistry, vol. 23, pp. 219-230, 2015. 
[36] B. Neppolian, H. C. Choi, S. Sakthivel, B. Arabindoo, and V. Murugesan, "Solar/UV-induced photocatalytic degradation of three commercial textile dyes," Journal of Hazardous Materials, vol. 89, no. 2-3, pp. 303-317, 2002.

[37] R. Saleh and N. F. Djaja, "Transition-metal-doped $\mathrm{ZnO}$ nanoparticles: synthesis, characterization and photocatalytic activity under UV light," Spectrochimica Acta Part A: Molecular and Biomolecular Spectroscopy, vol. 130, pp. 581-590, 2014.

[38] C. G. da Silva and J. L. Faria, "Photochemical and photocatalytic degradation of an azo dye in aqueous solution by UV irradiation," Journal of Photochemistry and Photobiology A: Chemistry, vol. 155, no. 1-3, pp. 133-143, 2003. 